\title{
Metadichol @ a novel nano lipid that inhibits In Vitro, SARS-COV-2 and a multitude of pathological viruses
}

Palayakotai R Raghavan ( $\nabla$ raghavan@nanorxinc.com )

Nanorx Inc

\section{Research Article}

Keywords: Covid-19, SARS-COV-2, Malaria, AHR, AR,COVID-19, ACE2, TMPRSS2, Furin, CD 147, VDR, Inverse agonist, Protean agonist, Metadichol, Nano formulation, inverse agonist, SARS, H1N1, Ebola, Zika, West Nile,

Posted Date: July 20th, 2020

DOl: https://doi.org/10.21203/rs.3.rs-34021/v4

License: (1) This work is licensed under a Creative Commons Attribution 4.0 International License. Read Full License 


\section{Abstract}

New pathogenic virus outbreaks, occurring with increasing regularity, are leading us to explore novel approaches, which will reduce the reliance on time-consuming vaccine modes to halt the outbreaks. The requirement is to find a universal approach to disarm any new and as yet unknown viruses as they appear. A promising approach could be targeting lipid membranes, which are common to all viruses and bacteria.

The ongoing pandemic of severe acute respiratory syndrome-coronavirus 2 (SARS-COV-2) has reaffirmed the importance of interactions between components of the host cell plasma membrane and the virus envelope as a critical mechanism of infection. Metadichol ${ }^{\circledR}$, a nano lipid emulsion, has been examined and shown to be a strong candidate to help stop the proliferation of SARS-COV-2.

Naturally derived substances, such as long-chain saturated lipid alcohols, reduce the infectivity of various types of viruses, including coronaviruses such as SARS-COV-2, by modifying lipid-dependent attachment to human host cells. SARS-COV-2 uses the receptor ACE2 for entry and the serine protease TMPRSS2 for S protein priming.

Metadichol ${ }^{\circledR}$, a nano lipid formulation of long-chain alcohols, has been shown to inhibit TMPRSS2 (EC50 $96 \mathrm{ng} / \mathrm{ml}$ ). Compared to the inhibitor camostat mesylate (EC50 $26000 \mathrm{ng} / \mathrm{ml}$ ), it is 270 times more potent. Additionally, Metadichol ${ }^{\circledR}$ is also a weak inhibitor of ACE2 at $31 \mu \mathrm{g} / \mathrm{ml}$. Further a live virus assay in Caco2 cells, Metadichol® inhibited SARS-CoV-2 replication with an EC90 of $0.16 \mu \mathrm{g} / \mathrm{ml}$.

\section{Introduction}

There is currently an increasing need for a broad-spectrum antimicrobial agent that could inactivate human pathogens, such as bacteria and viruses. Rapid resistance by microorganisms has propelled this approach to the development of focused drugs. The most recent trigger is the fear of a future pandemic caused by new, poorly studied virulent strains, such as the present SARS-COV-2.

\section{Background information on SARS-COV-2}

Severe acute respiratory syndrome coronavirus 2 (SARS-COV-2) (causative agent of COVID-19) is causing a pandemic 1 that has produced global havoc within a few months. Medically controlling a rapidly spreading viral pandemic utilizing specific antivirals and vaccines will prove expensive and time consuming and is accompanied by compromises on safety and efficacy. An alternative approach is to test molecules that are already proven safe for effectiveness against SARS-COV-2. Among the candidates being tested are camostat mesylate (a 35-year-old Japanese drug), Avigan (another Japanese drug) and Gilead Science Inc.'s remdesivir2. 
To enter a host cell, SARS-COV-2 requires transmembrane protease serine 2 (TMPRSS2)3, a serine protease, and angiotensin-converting enzyme 2 (ACE2) 4 to bind and thus facilitate its entry. Blocking both receptors can effectively stop the cell entry mechanism used by the virus.

TMPRSS2 is a protease that primes the spike protein of SARS-COV and the Middle East respiratory syndrome-related coronavirus (MERS-COV). Camostat mesylate (CM), an inhibitor of TMPRSS2, inhibited SARS-COV in a mouse model5,6. Hoffmann et al.7 determined that SARS-COV-2 requires TMPRSS2. They showed that CM blocks virus entry into the lungs. To date, there are no clinical data on the use of $\mathrm{CM}$ in patients.

The other receptor used by viruses to enter the host cell is ACE2. SARS-COV-2 has a spike (S) protein on its viral envelope (exterior) that binds to the transmembrane protein ACE2, which is present on human cells. ACE2 is essential for viral entry. However, ACE2 also regulates blood pressure and blood volume; blocking ACE2 would be detrimental to health. An approach that partially regulates ACE2 in concert with inhibition of TMPRSS2 would thus be an ideal solution.

\section{Lipids and viruses}

Viral envelope lipids play a role in both viral stability and infective capabilities. For example, substances that affect the lipid envelope, such as phospholipases, organic solvents, and surfactants, such as soaps, have been shown to affect viral infectivity. Causing envelope disintegration, they stop virus transmission to a new host. Active ingredients8 in a number of cleaning agents, wipes, and tissues target the viral lipid envelope to render the virions nonviable. Snipes and coworkers9 showed that saturated alcohols could inactivate viruses with chain lengths from 10 to 14 carbons. Their studies established that inactivation of enveloped viruses by lipids varies greatly, depending on both the nature of the lipid and the type of virus. Hilmarsson et al.10-12 studied the virucidal effects of medium- and long-chain (8 to 18 carbon) fatty alcohols and corresponding lipids against herpes simplex viruses (HSV-1 and HSV-2), respiratory syncytial virus (RSV), human parainfluenza virus type 2 (HPIV2) and enveloped viruses at various concentrations, times and $\mathrm{pH}$ levels. After a 10 -minute incubation at $37^{\circ} \mathrm{C}$ with a $10 \mathrm{mM}$ concentration, 14 of the lipids tested caused a 100000 -fold or more significant reduction in HSV titre. Testing between $\mathrm{pH} 7$ and 4.2 showed that a $\mathrm{pH}$ of 4.2 caused a more rapid inactivation of HSV-1 virus titre in one minute than higher $\mathrm{pH}$ values. These long-chain alcohols may act by penetrating the envelope of the virus by hydrophobic effects, making it permeable to small molecules and thus inactivating the virus; the degree of penetration into lipid membranes is based on the chain length of a lipid compared with the thickness of the membrane13.

Metadichol ${ }^{\circledR}$ is a nano lipid formulation of long-chain alcohols14. Metadichol has been shown to inhibit viruses in vitro and in vivo15-17. Metadichol was tested for its inhibitory actions against ACE2 and TMPRSS 2 and in an antiviral assay with SARS-COV-2. 


\section{Results And Discussion}

The results in Table 1 and 2 demonstrate Metadichol's direct antiviral effect against the SARS-COV-2 virus in Caco-2 cells, with an EC90 of $0.15 \mu \mathrm{g} / \mathrm{ml}$. Comparatively, this result indicates that Metadichol has a 2000-fold higher effectiveness than Remdesivir and 4000-fold potency over hydroxychloroquine phosphate18..

A previously published work 15 of antiviral data against other viruses is shown in Tables 3 and 4 . Raw data show the cytotoxicity of Metadichol without a virus present in Vero cells was measured by neutral red assay. When $>75 \%$ "toxicity" occurred in the absence of virus, no viral CPE value was reported.

These results suggest that it is toxic to cells at concentrations above $5 \mathrm{ug} / \mathrm{ml}$ in most cases. However, Metadichol is not toxic, as the LD50 is $5000 \mathrm{mg} / \mathrm{kg} 19-21$. It is likely that

Metadichol at higher concentrations behaves in a soap-mimicking manner by disrupting the lipid membrane, and at lower concentrations, it neutralizes the virus by a different mechanism.

Metadichol is not toxic to cell lines, but rather, it behaves as a "detergent" in neutralizing SARS- COV-2 and other pathogenic viruses shown in Table 5. Additionally, Metadichol ${ }^{\circledR}$ targets selectively cancer cells in this case Caco-2 cells. In a previous study22of Klotho gene expression in the cancer cell lines MiaPaca, Colo 205, and Panc1, Metadichol was seen to be toxic to cell lines above $1 \mu \mathrm{g} / \mathrm{ml}$. It is also toxic at $10 \mu \mathrm{g} / \mathrm{ml}$ in leukaemia cancer cells243

Metadichol also inhibits TMPRSS2 ( Table 6 figure 1,2) and is 270 -fold more potent than CM24 Metadichol moderately inhibits ACE2 ( Table 7, figures 3 and 4) and, in combination with TMPRSS2 inhibition, likely leads to a pronounced synergistic effect in overcoming viral entry. The reported results open the gateway to effective and safe therapies for COVID-19. Metadichol is a mild inhibitor of ACE2 ( table 7 and figures 4 and 6 ) but at the same time, not significant to affect the physiological functions of the host.

\section{Vitamin D and SARS-COV-2 infection}

An uncontrolled inflammatory response to SARS-COV-2 is the major cause of disease severity and death in patients with COVID-1925 and is associated with high levels of circulating cytokines, tumor necrosis factor (TNF), CCl2, C-reactive protein (CRP), and Ferritin.

Metadichol14 is an inhibitor of $\mathrm{CCl} 2$ (also known as MCP-1), TNF, NF-kB, and CRP, which is a surrogate marker for cytokine storms 26 and is associated with vitamin $D$ deficiency.

Vitamin D3 is generated in the skin through the action of UVB radiation, with 7- dehydrocholesterol generated in the skin, followed by a thermal reaction. Vitamin D3 is converted to 25(OH)D in the liver and then to $1,25(\mathrm{OH}) 2 \mathrm{D}$ (calcitriol) in the kidneys. Calcitriol binds to the nuclear vitamin $\mathrm{D}$ receptor (VDR); a 
DNA-binding protein interacts with regulatory sequences near target genes that participate genetically and epigenetically in the transcriptional output of genes needed for function27. Vitamin $D$ reduces the risk of infections by mechanisms that include inducing cathelicidins and defensins 28 , resulting in lowered viral replication rates and reducing concentrations of pro-inflammatory cytokines29.

Supplementation with $4000 \mathrm{IU} / \mathrm{d}$ vitamin D decreased dengue virus infection30. Inflammatory cytokine levels increase in viral and bacterial infections, as seen in COVID-19 patients. Vitamin D can reduce the production of pro- inflammatory Th1 cytokines, such as TNF and interferon (IFN)31.

Vitamin $D$ is a modulator of adaptive immunity32 and suppresses responses mediated by $T$ helper type 1 (Th1) cells primarily by repressing the production of the inflammatory cytokines interleukin (IL) -2 and IFN-gamma33. Additionally, 1,25(OH)2D3 promotes cytokine production by T helper type 2 (Th2) cells, which helps enhance the indirect suppression of Th1 cells by complementing this suppression with actions mediated by a multitude of cell types 34 .

1,25(OH)2D3 promotes $T$ regulatory cell induction, thereby inhibiting inflammatory processes 35 . It is known that COVID-19 is associated with the increased production of pro- inflammatory cytokines, elevated CRP levels, increased risk of pneumonia, sepsis, acute respiratory distress syndrome (ARDS), and heart failure36. Case fatality rates (CFRs) in China were $6 \%-10 \%$ for those with cardiovascular disease, chronic respiratory tract disease, diabetes, and hypertension37. Metadichol is a inverse agonist/protean agonist 14 of VDR ie it binds at the same site as calcitriol but has different properties. It is the only known inverse agonist to VDR known in medical literature.

\section{Telomerase and viral infections}

Metadichol at one picogram increases h-TERT (telomerase) expression by 16 -fold38. Viral infection places a significant strain on the body. CD8 T cells that mediate adaptive immunity39 to protect the body from microbial invaders can easily reach their Hayflick limit by depleting their telomeres40. This possibility is more likely if telomeres are already short. Infections put enormous strain on immune cells to replicate. Naive T and B cells are particularly important when our bodies encounter new pathogens, such as SARS-COV-2. The quantity of these cells is crucial for useful immune function.

\section{AHR and viral infections}

One of the major issues with infected COVID-19 patients has been respiratory failure. It has been suggested that the aryl hydrocarbon receptor (AHR) is activated during coronavirus infections, impacting antiviral immunity and lung cells associated with repair41. Signalling via AHR may dampen the immune response against coronavirus42. It has been reported that although some signalling is needed for coronavirus replication, excessive activation of this pathway may be deleterious for the virus. AHR limits activation and interferes with multiple antiviral immune mechanisms, including IFN-I production and intrinsic immunity. Yamada et al.43 suggested that AHR (the constitutive aryl hydrocarbon receptor) 
signalling constrains type I IFN-mediated antiviral innate defence and suggested a need to block constitutive AHR activity; only an inverse agonist can dampen this activity. We have shown that Metadichol® binds to AHR as an inverse/protean agonist44 and thus can reduce complications attributed to uncontrolled inflammation and cytokine storms.

\section{Vitamin $\mathrm{C}$ and viral infections}

In infectious diseases, there is also a need to boost innate and adaptive immunity. The micronutrients with the most robust evidence for immune support are vitamins $C$ and D. Vitamin $C$ is essential for a healthy and functional host defence. The pharmacological application of vitamin $\mathrm{C}$ enhances immune function45. Vitamin $\mathrm{C}$ has antiviral properties leading to inhibition of the replication of HSV-1, poliovirus type 1 , influenza virus type46, and rabies virus in vitro47.

Vitamin C deficiency reduces cellular48-52and humoral immune responses, and treatment of healthy subjects promoted and enhanced natural killer (NK) cell activities53, underlining the immunological importance of vitamin C54,55 and supporting its role as a crucial player in various aspects of immune cell functions, such as immune cell proliferation and differentiation, in addition to its anti-inflammatory properties. Moreover, the newly characterized hydroxylase enzymes, which regulate the activity of hypoxia-inducible factor gene transcription and cell signalling of immune cells, need vitamin $\mathrm{C}$ as a cofactor for optimal activity56-58. Metadichol administration increases vitamin C levels endogenously by recycling vitamin $\mathrm{C}$ and produces levels not reached by oral intake, and those reached bring about changes in improving diverse biomarkers59-61.

\section{Gene cluster network analysis}

The present drug discovery paradigm is based on the idea of one gene-one target, one disease. It has become clear that it is difficult to achieve single target specificity. Thus, the need to transition from targeting a single gene to targeting multiple genes is likely to become more attractive, leading to blocking multiple paths of disease progression62,63. Gene network analysis can provide a minimum set of genes that can form the basis for targeting diseases. This clustering network of genes can modulate gene pathways and biological networks. We used www.ctdbase.org64, which has curated genes show in Table 8 relevant to COVID-19. Table 9 lists genes and diseases states that they are involved in.

We can filter the 13 genes to a set of 5 genes: TNF, CCL2, ACE2, TMPRSS2 are modulated by Metadichol and AGT, which is part of the renin-angiotensin system (RAS) network that ACE2 is a part of (Figure 5). A similar analysis of these network genes shows that they are closely networked in diseases, with a highly significant p-value. These five genes are closely related, and the network generated, is shown in Figure 6 , using www.innatedb.org65.

This analysis integrates known interactions and pathways from major public databases. 
The highlighted ones are SIRT1, AR (androgen receptor), and FOS. Glinsky66 suggested vitamin D as a potential mitigation agent in preventing SARS-COV-2 entry. Metadichol binds to VDR, which controls the expression of FOS67. AR also controls the expression of FOS, as well as that of TMPRSS2. Figure 7, generated below using PAC068, shows the gene network and regulation relationships. VDR controls FOS expression, FOS controls AGT, AGT controls the expression of AGTR1 and ACE, and AR controls the expression of TMPRSS2.

Wambier and Goren69 suggested that SARS-COV-2 infection is likely to be androgen mediated. The first step to infection is the priming of the SARS-COV-2 spike proteins by TMPRSS2, which also cleaves ACE2 for augmented viral entry. This pathway is seen in the network (Figure 8). SIRT1 plays an active role in enhancing immunity in viral infections70

Proteases such as Furin71 and Adam-17 have been described to activate the spike protein in vitro for viral spread and pathogenesis in infected hosts. VDR controls Furin expression, mediated through its interaction with SRC72. Adam-17 is regulated via CEPBP73,74, which is involved in the regulation of genes involved in immune and inflammatory responses. Recently, Ulrich and Pillat75 proposed that CD147, similar to ACE2, is another receptor used for viral entry. CD147 is a known receptor76 for the parasite that causes malaria in humans, Plasmodium falciparum. Metadichol (see Ref6, US patent $9,006,292)$ inhibits the malarial parasite.

The key to entry into cells by SARS-COV-2 is ACE2, which, when endocytosed with SARS-COV-2, results in a reduction in ACE2 on cells and an increase in serum Angiostensin II77. Angiostensin II acts as a vasoconstrictor and a pro-inflammatory cytokine (Figure 9) via AT1R78. The Angiostensin II-AT1R axis leads to a pro-inflammatory state79, leading to infections through activation of NF-KB and to increased IL-6 levels in multiple inflammatory and autoimmune diseases 80 .

The dysregulation of angiotensin 2 downstream of ACE2 leads to the cytokine release that is seen in COVID-19 patients, resulting in increased TNF levels that lead to elevated IL-6, CCl2, and CRP levels. Cytokine storms81 result in ARDS.

\section{Controlling cytokine storms}

A cytokine storm develops after an initial immune response by the induction of cytokines. The response to SARS-COV-2 leads to inflammation. There are increased levels of the pro- inflammatory cytokines IL6, IL-18, TNF, and IL-1-beta by macrophages and of IFN-gamma by NK cells.

Figure 9 was generated, using of PACO (www.pathwcommons.org), shows the cytokine relationship network. The cytokines can activate T cells, which lead to tissue damage and infection in the lungs. Infiltration of T cells can also result from the upregulation of adhesion molecules, such as ICAM1, by lung endothelial cells. Metadichol is an inhibitor (see Ref14, US patent 8,722,093) of TNF alpha in vivo, and ICAM 1 and CCI 2 depress the hyper inflammatory cytokine response caused by SARS-COV- 2 and, at the 
same time, enhance innate and adaptive immunity through the VDR pathways and increased vitamin C levels. Metadichol, by its binding

to VDR, leads to a network of gene control of the cytokine storms illustrated in Figure 6, bringing about homeostasis.

\section{Clinical}

A pilot study done by a third party Kasturaba Hospital in Mumbai India, on thirty COVID-19 patients with minor symptoms showed the absence of a virus in $75 \%$ of patients after 4 days of Metadichol treatment @ $20 \mathrm{mg}$ per day. To validate this further, we have been initiated a larger study in collaboration with government agencies where we will have Metadichol treatment group and control groups, with only Standard Care. We hope to communicate these results in the near future..

\section{Summary And Conclusions}

Metadichol inhibits SARS-COV-2 entry into host cells by inhibiting TMPRSS2 and partial inhibition of ACE2 and boosts the antiviral response by enhancing innate and adaptive immunity through the vitamin D pathway and antiviral activity by endogenously increasing vitamin $C$ levels. In addition, telomerase activity can also play a key role in maintaining the levels of naive $T$ and $B$ cells needed to fight infections. Metadichol modulates cytokine storms, as it is an inhibitor of TNF, ICAM1 and CCL2, which, as shown, play a key role with other cytokines. Co morbidities associated82,83 with COVID-19, such as hypertension and diabetes 84,85 , are also controlled by Metadichol, which could certainly improve the long-term prognosis for the affected patient population. These actions on multiple genes and via multiple pathways bring about homeostasis and prevent SARS-COV-2 infections. Metadichol's 86 actions on multiple genes and proteins lead to over 2000 unique interactions with other genes and result in a network that helps bring about homeostasis.

Metadichol is a safe, nontoxic product made from renewable sources and have been commercially available for the last six years, with no reported side effects. This unique property allows for the use of Metadichol as an immune modulator to prevent future occurrence of SARS- COV-2 and possibly other infections being predicted, facilitating a rapid return to normal human social and economic activity worldwide.

\section{References}

1. Morse, J. S., Lalonde, T., Xu, S. \& Liu, W. R. Learning from the past: possible urgent prevention and treatment options for severe acute respiratory infections caused by 2019- nCoV. Chembiochem 21, 730-738 (2020). 
2. Li, G. \& De Clercq, E. Therapeutic options for the 2019 novel coronavirus (2019-nCoV). Nat. Rev. Drug Discov. 19, 149-150 (2020).

3. Jankun, J. COVID-19 pandemic; transmembrane protease serine 2 (TMPRSS2) inhibitors as potential drugs. Translation 7, 1-5 (2020).

4. Hamming, I. et al. The emerging role of ACE2 in physiology and disease. Pathol. 212, 1-11 (2007).

5. Rabaan, A. A. Middle East respiratory syndrome coronavirus: five years later. Rev. Respir. Med. 11, 901-912 (2017).

6. Zhou, Y. et al. Protease inhibitors targeting coronavirus and filovirus entry. Res. 116, 76-84 (2015).

7. Hoffmann, M. et al. SARS- CoV-2 cell entry depends on ACE2 and TMPRSS2. A clinically proven protease inhibitor blocks it. Cell 181, 271-280 (2020).

8. Greatorex, J. S. et al. Effectiveness of common household cleaning agents in reducing the viability of human influenza A/H1N1. PLoS One 5, e8987 (2010).

9. Snipes, W., Person, S., Keller, G., Taylor, W. \& Keith, A. Inactivation of lipid-containing viruses by longchain alcohols. Agents Chemother. 11, 98-104 (1977).

10. Hilmarsson, H., Kristmundsdottir, T. \& Thormar, H. Virucidal activities of medium- and long-chain fatty alcohols, fatty acids and monoglycerides against herpes simplex virus types 1 and 2: comparison at different pH levels. APMIS 113, 58-65 (2005).

11. Hilmarsson, H., Larusson, L. V. \& Thormar, H. Virucidal effect of lipids on visna virus, a lentivirus related to HIV. Virol. 151, 1217-1224 (2006).

12. Hilmarsson, H., Traustason, B. S., Kristmundsdóttir, T. \& Thormar, H. Virucidal activities of mediumand long-chain fatty alcohols and lipids against respiratory syncytial virus and parainfluenza virus type 2: comparison at different pH levels. Virol. 152, 2225-2236 (2007).

13. Isaacs, C. E., Kims, K. \& Thormar, H. Inactivation of enveloped viruses in human bodily fluids by purified lipids. N. Y. Acad. Sci. 724, 457-464 (1994).

14. Raghavan, P. R. U.S patents 8,722, 094 (2014) ; 9,034,383 (2015) ; 9,006,292(2015).

15. Raghavan, P. R. In vitro inhibition of zika virus by Metadichol ${ }^{\circledR}$, a novel nano emulsion lipid. Immunol. Tech. Infect. Dis. 5, 2-6 (2016).

16. Raghavan, P. R. Inhibition of Dengue and other enveloped viruses by Metadichol $\circledast$, a novel Nanoemulsion Lipid. Heal. Outcomes 8, 19-25 (2016).

17. Raghavan, P. R. Inhibition of viruses by Metadichol®: A novel nano emulsion Pediatr. Infect. Dis. 2, 35 (2017).

18. Jin, Z., Du, X. \& Yang, H. Structure of Mpro from SARS-CoV-2 and discovery of its inhibitors. Nature 582, 289-293 (2020).

19. Aleman, C. et al. A 12-month study of policosanol oral toxicity in Sprague Dawley Toxicol. Lett. 70, 77-87 (1994).

20. Alemán, C. L. et al. Carcinogenicity of policosanol in sprague dawley rats: a 24 month study. Carcinog. Mutagen. 14, 239-249 (1994). 
21. Alemán, C. L. et al. Carcinogenicity of policosanol in mice: an 18-month study. Food Chem. Toxicol. 33, 573-578 (1995).

22. Raghavan, P. R. Metadichol ${ }^{\circledR}$ a novel agonist of the anti-aging klotho gene in cancer cell lines. Cancer Sci. Ther. 10, 351-357 (2018)..

23. R. Raghavan unpublished results.

24. Uno, Y. Camostat mesilate therapy for COVID-19. Preprint at https://pubmed.ncbi.nlm.nih.gov/32347443 (2020).

25. Merad, M. \& Martin, J. C. Pathological inflammation in patients with COVID-19: a key role for monocytes and macrophages. Rev. Immunol. 20, 355-362 (2020).

26. Daneshkhah, A. et al. The possible role of Vitamin $D$ in suppressing cytokine storm and associated mortality in COVID-19 patients. medRxiv 4, 20058578 (2020).

27. Pike, J. W. \& Christakos, S. Biology and mechanisms of action of the Vitamin D hormone. Metab. Clin. N. Am. 46, 815-843 (2017).

28. Liu, P. T. et al. Convergence of IL-1beta and VDR activation pathways in human TLR2/1-induced antimicrobial responses. PLoS One 4, e5810 (2009).

29. Wang, T.-T. et al. Cutting edge: 1,25-dihydroxyvitamin D3 is a direct inducer of antimicrobial peptide gene expression. Immunol. 173, 2909-2912 (2004).

30. Martínez-Moreno, J., Hernandez, J. C. \& Urcuqui-Inchima, S. Effect of high doses of vitamin D supplementation on dengue virus replication, Toll-like receptor expression, and cytokine profiles on dendritic cells. Cell Biochem. 464, 169-180 (2020).

31. Spilianakis, C. G., Lee, G. R. \& Flavell, R. A. Twisting the Th1/Th2 immune response via the retinoid X receptor: lessons from a genetic approach. J. Immunol. 35, 3400- 3404 (2005).

32. Wei, R. \& Christakos, S. Mechanisms underlying the regulation of innate and adaptive immunity by Vitamin D. Nutrients 7, 8251-8260 (2015).

33. Cantorna, M. T., Snyder, L., Lin, Y.-D. \& Yang, L. Vitamin D and 1,25(OH)2D regulation of T cells. Nutrients 7, 3011-3021 (2015).

34. Cantorna, M. T. Mechanisms underlying the effect of vitamin D on the immune Proc. Nutr. Soc. 69, 286-289 (2010).

35. Lemire, J. M. et al. 1,25-dihydroxyvitamin D3 suppresses human T helper/inducer lymphocyte activity in vitro. Immunol. 134, 3032-3035 (1985).

36. Huang, C. et al. Clinical features of patients infected with 2019 novel coronavirus in Wuhan, China. Lancet (London, England) 395, 497-506 (2020).

37. Wang, D. et al. Clinical characteristics of 138 hospitalized patients with 2019 novel coronavirusinfected pneumonia in Wuhan, China. JAMA 323, 1061-1069 (2020).

38. Raghavan, P. R. Metadichol ${ }^{\circledR}$ and CD33 expression in umbilical cord cells. Stem Cell Res. Ther. 9, 446 (2019).

39. Weng, N. P. Telomere and adaptive immunity. Ageing Dev. 129, 60-66 (2008). 
40. Hodes, R. J., Hathcock, K. S. \& Weng, N. P. Telomeres in T and B cells. Rev. Immunol. 2, 699-706 (2002).

41. Poppe, M. et al. The NF-KB-dependent and -independent transcriptome and chromatin landscapes of human coronavirus 229E-infected cells. PLoS Pathog. 13, e1006286 (2017).

42. Giovannoni, F. et al. AHR is a Zika virus host factor and a candidate target for antiviral therapy. Neurosci. 22, 729-740 (2019).

43. Yamada, T. et al. Constitutive aryl hydrocarbon receptor signaling constrains type I interferonmediated antiviral innate defense. Immunol. 17, 687-694 (2016).

44. Raghavan, P. R. Metadichol ®. A novel inverse agonist of aryl hydrocarbon receptor (AHR) and NRF2 inhibitor. Cancer Sci. Ther. 9, 661-668 (2017).

45. Heuser, G. \& Vojdani, A. Enhancement of natural killer cell activity and T and B cell function by buffered Vitamin $C$ in patients exposed to toxic chemicals: the role of protein kinase-C. Immunotoxicol. 19, 291-312 (1997).

46. Furuya, A. et al. Antiviral effects of ascorbic and dehydroascorbic acids in vitro. J. Mol. Med. 22, 541545 (2008).

47. $\mathrm{Kim}, \mathrm{H}$. et al. Red ginseng and vitamin $\mathrm{C}$ increase immune cell activity and decrease lung inflammation induced by influenza A virus/H1N1 infection. Pharm. Pharmacol. 68, 406-420 (2016).

48. Madhusudana, S. N., Shamsundar, R. \& Seetharaman, S. In vitro inactivation of the rabies virus by ascorbic acid. J. Infect. Dis. 8, 21-25 (2004).

49. Alvares, O., Altman, L. C., Springmeyer, S., Ensign, W. \& Jacobson, K. The effect of subclinical ascorbate deficiency on periodontal health in nonhuman primates. Periodontal. Res. 16, 628-636 (1981).

50. Goldschmidt, M. C., Masin, W. J., Brown, L. R. \& Wyde, P. R. The effect of ascorbic acid deficiency on leukocyte phagocytosis and killing of actinomyces viscosus. J. Vitam. Nutr. Res. 58, 326-334 (1988).

51. Wintergerst, E. S., Maggini, S. \& Hornig, D. H. Immune-enhancing role of Vitamin $C$ and zinc and effect on clinical conditions. Nutr. Metab. 50, 85-94 (2006).

52. Woo, A. et al. Vitamin C acts indirectly to modulate isotype switching in mouse B Anat. Cell Biol. 43, 25-35 (2010).

53. Carr, A. C. \& Maggini, S. Vitamin C and immune function. Nutrients 9, 1211 (2017).

54. Washko, P., Rotrosen, D. \& Levine, M. Ascorbic acid in human neutrophils. J. Clin. Nutr. 54, 1221S1227S (1991).

55. Kuiper, C. \& Vissers, M. C. M. Ascorbate as a co-factor for fe- and 2-oxoglutarate dependent dioxygenases: physiological activity in tumor growth and progression. Oncol. 4, 359 (2014).

56. Loenarz, C. \& Schofield, C. J. Physiological and biochemical aspects of hydroxylations and demethylations catalyzed by human 2-oxoglutarate oxygenases. Trends Biochem. Sci. 36, 7-18 (2011). 
57. Flashman, E., Davies, S. L., Yeoh, K. K. \& Schofield, C. J. Investigating the dependence of the hypoxiainducible factor hydroxylases (factor inhibiting HIF and prolyl hydroxylase domain 2) on ascorbate and other reducing agents. J. 427, 135-142 (2010).

58. Kuiper, C., Dachs, G. U., Currie, M. J. \& Vissers, M. C. M. Intracellular ascorbate enhances hypoxiainducible factor (HIF)-hydroxylase activity and preferentially suppresses the HIF-1 transcriptional response. Free Radic. Biol. Med. 69, 308-317 (2014).

59. Raghavan, P. R. Metadichol ${ }^{\circledR}$, Vitamin $C$ and GULO gene expression in mouse adipocytes. Med. 10, 426 (2017).

60. Raghavan, P. R. Metadichol ${ }^{\circledR}$ and Vitamin C increase in vivo, an open-label Vitam. Miner. 6, 163 (2017).

61. Raghavan, P. R. Metadichol® induced high levels of Vitamin C: case studies. Miner. 6, 169 (2017).

62. Creixell, P. et al. Pathway and network analysis of cancer genomes. Methods 12, 615-621 (2015).

63. Barabási, A.-L., Gulbahce, N. \& Loscalzo, J. Network medicine: a network-based approach to human disease. Rev. Genet. 12, 56-68 (2011).

64. Davis, A. P. et al. The comparative toxicogenomics database: update 2019. Nucleic Acids Res. 47, D948-D954 (2019).

65. Breuer, K. et al. InnateDB: systems biology of innate immunity and beyond-recent updates and continuing curation. Nucleic Acids Res. 41, D1228-D1233 (2013).

66. Glinsky, G. Genomics-guided molecular maps of coronavirus targets in human cells: a path toward the repurposing of existing drugs to mitigate the pandemic. arXiv:2003.13665 (2020).

67. Meyer, M. B., Goetsch, P. D. \& Pike, J. W. VDR/RXR and TCF4/ $\beta$-catenin cistromes in colonic cells of colorectal tumor origin: impact on c-FOS and c-MYC gene expression. Endocrinol. 26, 37-51 (2012).

68. Rodchenkov, I. et al. Pathway commons 2019 update: integration, analysis and exploration of pathway data. Nucleic Acids Res. 48, D489-D497 (2020).

69. Wambier, C. G. \& Goren, A. Severe acute respiratory syndrome coronavirus 2 (SARS- CoV-2) infection is likely to be androgen mediated. Am. Acad. Dermatol. 83, 308-309 (2020).

70. Lin, Z. \& et al. Sirt involvement in virus-mediated diseases. JSM Microbiol. 1, 1006 (2013).

71. Ma, Y. C. et al. The tyrosine kinase c-Src directly mediates growth factor-induced Notch- 1 and Furin interaction and Notch-1 activation in pancreatic cancer cells. PLoS One 7, e33414 (2012).

72. Buitrago, C., Vazquez, G., De Boland, A. R. \& Boland, R. L. Activation of Src kinase in skeletal muscle cells by 1,25-(OH)2-vitamin D3 correlates with tyrosine phosphorylation of the vitamin D receptor (VDR) and VDR-Src interaction. Cell. Biochem. 79, 274-281 (2000).

73. Marchwicka, A. \& Marcinkowska, E. Regulation of expression of CEBP genes by variably expressed Vitamin $\mathrm{D}$ receptor and retinoic acid receptor a in human acute myeloid leukemia cell lines. J. Mol. Sci. 19, 1918 (2018).

74. Arcidiacono, M. V., Yang, J., Fernandez, E. \& Dusso, A. The induction of C/EBP $\beta$ contributes to vitamin D inhibition of ADAM17 expression and parathyroid hyperplasia in kidney disease. Dial. Transplant. 
30, 423-433 (2015).

75. Ulrich, H. \& Pillat, M. M. CD147 as a target for COVID-19 treatment: suggested effects of azithromycin and stem cell engagement. Cell Rev. Rep. 16, 434-440 (2020).

76. Crosnier, C. et al. Basigin is a receptor essential for erythrocyte invasion by Plasmodium falciparum. Nature 480, 534-537 (2011).

77. Kuba, K. et al. A crucial role of angiotensin converting enzyme 2 (ACE2) in SARS coronavirus-induced lung injury. Med. 11, 875-879 (2005).

78. Eguchi, S., Kawai, T., Scalia, R. \& Rizzo, V. Understanding angiotensin II type 1 receptor signaling in vascular pathophysiology. Hypertension 71, 804-810 (2018).

79. Murakami, M., Kamimura, D. \& Hirano, T. Pleiotropy and specificity: insights from the interleukin 6 family of cytokines. Immunity 50, 812-831 (2019).

80. de Wit, E., van Doremalen, N., Falzarano, D. \& Munster, V. J. SARS and MERS: recent insights into emerging coronaviruses. Rev. Microbiol. 14, 523-534 (2016).

81. Pedersen, S. F. \& Ho, Y.-C. SARS-CoV-2: a storm is raging. Clin. Investig. 130, 2202- 2205 (2020).

82. Guo, W. et al. Diabetes is a risk factor for the progression and prognosis of COVID19. Diabetes/Metab. Res. Rev. 202, e3319 (2020).

83. Wu, C. et al. Risk factors associated with acute respiratory distress syndrome and death in patients with coronavirus disease 2019 pneumonia in Wuhan, China. JAMA Intern. Med. 13, e200994 (2020).

84. Raghavan, P. R. Systolic and diastolic BP control in metabolic syndrome patients with Metadichol® a novel nano emulsion lipid. Cardiol. Cardiovasc. Ther. 5, 555660 (2017).

85. Raghavan, P. R. Metadichol and type 2 diabetes a case report. Sci. Heal Outcomes 8, 5- 10 (2106).

86. Raghavan, P. https://www.researchgate.net/profile/Palayakotai_Raghavan/publications.

\section{Tables}

Table 1. In vitro antiviral assay results

\begin{tabular}{|l|l|l|l|}
\hline & CC50 & EC90 & SI90 \\
\hline Metadichol $(\mu \mathrm{g} / \mathrm{ml})$ & 4 & 0.15 & 20 \\
\hline M128533 $(\mu \mathrm{g} / \mathrm{ml})$ & $>10$ & 0.2 & $>33$ \\
\hline
\end{tabular}

CC50: $50 \%$ cytotoxic concentration of compound without virus added; EC50: $50 \%$ effective antiviral concentration;

EC90: calculated concentration to reduce virus yield by 1 log (90\%); SI: CC50/EC50. 
Table 2. Cytotoxicity and virus yield data for each concentration of Metadichol tested

\begin{tabular}{|c|c|c|}
\hline Metadichol Concentration $(\mu \mathrm{g} / \mathrm{ml})$ & Cytotoxicity (\%) & $\begin{array}{c}\text { Virus Titre (CCID50 per 0.1 } \\
\mathrm{ml})\end{array}$ \\
\hline 100 & $100 \%$ & $<0.7$ \\
\hline 32 & $100 \%$ & $<0.7$ \\
\hline 10 & $83 \%$ & $<0.7$ \\
\hline 3.2 & $54 \%$ & 4.3 \\
\hline 1 & $17 \%$ & 1.5 \\
\hline 0.3 & $26 \%$ & 5.7 \\
\hline 0.1 & $26 \%$ & 5.3 \\
\hline 0.03 & & 0.7 \\
\hline
\end{tabular}

Table 3. Raw data for cytotoxicity of Metadichol without virus present, as measured by neutral red assay

\begin{tabular}{|c|c|c|c|c|c|c|c|c|}
\hline $\begin{array}{l}\text { Units are } \mu \mathrm{g} / \mathrm{ml} \text { unle } \\
\text { noted }\end{array}$ & & & & & & & & \\
\hline Metadichol $(\mu \mathrm{g} / \mathrm{ml})$ & Adenovirus & Tacaribe & $\begin{array}{l}\text { Rift } \\
\text { valley }\end{array}$ & SARS & $\begin{array}{l}\text { Japanese } \\
\text { encephalitis }\end{array}$ & $\begin{array}{l}\text { West Nile } \\
\text { virus }\end{array}$ & \multicolumn{2}{|c|}{$\begin{array}{l}\text { Yellow fever Powassan } \\
\text { virus }\end{array}$} \\
\hline 500 & $95 \%$ & $98 \%$ & $96 \%$ & $96 \%$ & $100 \%$ & $100 \%$ & $100 \%$ & $100 \%$ \\
\hline 160 & $92 \%$ & $98 \%$ & $96 \%$ & $95 \%$ & $100 \%$ & $100 \%$ & $100 \%$ & $100 \%$ \\
\hline 50 & $90 \%$ & $97 \%$ & $97 \%$ & $95 \%$ & $100 \%$ & $100 \%$ & $100 \%$ & $100 \%$ \\
\hline 16 & $85 \%$ & $95 \%$ & $81 \%$ & $92 \%$ & $88 \%$ & $77 \%$ & $98 \%$ & $100 \%$ \\
\hline 5 & $0 \%$ & $23 \%$ & $26 \%$ & $35 \%$ & $33 \%$ & $28 \%$ & $35 \%$ & $44 \%$ \\
\hline 1.6 & $0 \%$ & $2 \%$ & $10 \%$ & $15 \%$ & $12 \%$ & $14 \%$ & $19 \%$ & $6 \%$ \\
\hline 0.5 & $0 \%$ & $3 \%$ & $9 \%$ & $0 \%$ & $2 \%$ & $3 \%$ & $2 \%$ & $0 \%$ \\
\hline 0.16 & $0 \%$ & $17 \%$ & $3 \%$ & $0 \%$ & $0 \%$ & $0 \%$ & $4 \%$ & $0 \%$ \\
\hline CC50 & 9.90 & 7.30 & 8.40 & 6.70 & 7.20 & 8.50 & 5.00 & 5.1 \\
\hline
\end{tabular}


Table 4 Antiviral assay of Metadichol against various viruses, as measured by neutral red assay

\begin{tabular}{|c|c|c|c|c|c|c|c|c|}
\hline $\begin{array}{l}\text { Metadichol } \\
(\mu \mathrm{g} / \mathrm{ml})\end{array}$ & Adenovirus & Tacaribe & $\begin{array}{l}\text { Rift valley } \\
\text { fever }\end{array}$ & SARS & $\begin{array}{l}\text { Japanese } \\
\text { encephalitis }\end{array}$ & $\begin{array}{l}\text { West } \\
\text { Nile }\end{array}$ & $\begin{array}{l}\text { Yellow } \\
\text { fever }\end{array}$ & Powassan \\
\hline 5 & $100 \%$ & $31 \%$ & $100 \%$ & $0 \%$ & $56 \%$ & $84 \%$ & $70 \%$ & $53 \%$ \\
\hline 1.6 & $100 \%$ & $69 \%$ & $100 \%$ & $52 \%$ & $87 \%$ & $100 \%$ & $73 \%$ & $100 \%$ \\
\hline 0.5 & $100 \%$ & $97 \%$ & $100 \%$ & $100 \%$ & $100 \%$ & $100 \%$ & $95 \%$ & $100 \%$ \\
\hline 0.16 & $100 \%$ & $100 \%$ & $100 \%$ & $100 \%$ & $100 \%$ & $100 \%$ & $96 \%$ & $100 \%$ \\
\hline EC50 & $>9.9$ & 2.8 & $>8.4$ & 1.7 & $>7.2$ & $>8.5$ & $>5$ & $>5.1$ \\
\hline
\end{tabular}

Table 5. List of viruses inhibited by Metadichol in vitro

\begin{tabular}{|l|l|}
\hline Adenovirus & Rift valley \\
\hline Japanese encephalitis & Marburg \\
\hline Tacaribe & SARS \\
\hline Powassan & Respiratory syncytial virus \\
\hline Zika & Chikungunya \\
\hline Ebola & Influenza A (H1N1) \\
\hline Yellow fever & Dengue \\
\hline West Nile virus & HIV \\
\hline
\end{tabular}

Table 6. TMPRSS2 assay data 


\begin{tabular}{|c|c|c|c|c|}
\hline Sample & Concentration & RFU & \% Inhibition & IC50 \\
\hline Control & 0 & 43233358 & 0.00 & \\
\hline \multirow[t]{7}{*}{ Metadichol (ng/ml) } & 1.56 & 41305150 & 4.46 & $96.65 \mathrm{ng} / \mathrm{m}$ \\
\hline & 3.12 & 39329385 & 9.03 & \\
\hline & 6.25 & 36713767 & 15.08 & \\
\hline & 12.5 & 33778222 & 21.87 & \\
\hline & 25 & 30695684 & 29.00 & \\
\hline & 50 & 26087008 & 39.66 & \\
\hline & 100 & 16009312 & 62.97 & \\
\hline \multirow[t]{7}{*}{ Camostat mesylate $(\mu \mathrm{g} / \mathrm{ml})$} & 0.78 & 37984828 & 12.14 & $26.46 \mathrm{ug} / \mathrm{m}$ \\
\hline & 1.56 & 35235186 & 18.50 & \\
\hline & 3.125 & 31685728 & 26.71 & \\
\hline & 6.25 & 29234396 & 32.38 & \\
\hline & 12.5 & 23276839 & 46.16 & \\
\hline & 25 & 18931887 & 56.21 & \\
\hline & 50 & 8797988 & 79.65 & \\
\hline
\end{tabular}

Table 7 ACE2 assay data 


\begin{tabular}{|c|c|c|c|c|}
\hline Sample & Concentration $(\mu \mathrm{g} / \mathrm{ml})$ & RFU & $\%$ Inhibition & $\begin{array}{l}\text { IC50 } \\
(\mu \mathrm{g} / \mathrm{ml})\end{array}$ \\
\hline Control & 0 & 308315546 & 0.00 & \\
\hline \multirow[t]{7}{*}{ Metadichol } & 0.125 & 290309918 & 5.84 & 30.15 \\
\hline & 0.25 & 260064163 & 15.65 & \\
\hline & 0.5 & 249149792 & 19.19 & \\
\hline & 1 & 240301136 & 22.06 & \\
\hline & 10 & 212275253 & 31.15 & \\
\hline & 20 & 187702504 & 39.12 & \\
\hline & 40 & 139821100 & 54.65 & \\
\hline \multirow[t]{6}{*}{ DX600 } & 0.0156 & 252855648 & 17.99 & 0.1027 \\
\hline & 0.031 & 231028864 & 25.07 & \\
\hline & 0.0625 & 193810784 & 37.14 & \\
\hline & 0.125 & 145881248 & 52.68 & \\
\hline & 0.25 & 127485752 & 58.65 & \\
\hline & 0.5 & 111498760 & 63.84 & \\
\hline
\end{tabular}

Table 8. COVID-19 and 13 curated genes

\begin{tabular}{|l|l|l|}
\hline CCL2 & IL6 & IL7 \\
\hline TNF & TMPRSS2 & ACE2 \\
\hline IL10 & CCL3 & AGT \\
\hline IL2 & IL8 & IL2RA \\
\hline CSF3 & & \\
\hline
\end{tabular}

Table 9. Disease network of the 13 curated genes 


\begin{tabular}{|c|c|c|c|c|}
\hline Disease name & Disease categories & $\begin{array}{l}\text { Corrected } \\
\text { P-value }\end{array}$ & $\begin{array}{l}\text { Annotated } \\
\text { gene } \\
\text { quantity }\end{array}$ & Annotated genes \\
\hline COVID-19 & $\begin{array}{l}\text { Respiratory tract disease, viral } \\
\text { disease }\end{array}$ & $3.10 \mathrm{E}-47$ & 13 & $\begin{array}{l}\text { ACE2, AGT, CCL2, CCL3, CSF3, CXCL10, } \\
\text { IL10, IL2, IL2RA, IL6, IL7, TMPRSS2, TNF }\end{array}$ \\
\hline Pneumonia, viral & $\begin{array}{l}\text { Respiratory tract disease, viral } \\
\text { disease }\end{array}$ & $4.34 \mathrm{E}-46$ & 13 & $\begin{array}{l}\text { ACE2, AGT, CCL2, CCL3, CSF3, CXCL10, } \\
\text { IL10, IL2, IL2RA, IL6, IL7, TMPRSS2, TNF }\end{array}$ \\
\hline $\begin{array}{l}\text { Coronaviridae } \\
\text { infections }\end{array}$ & Viral disease & $1.74 \mathrm{E}-44$ & 13 & $\begin{array}{l}\text { ACE2, AGT, CCL2, CCL3, CSF3, CXCL10, } \\
\text { IL10, IL2, IL2RA, IL6, IL7, TMPRSS2, TNF }\end{array}$ \\
\hline Coronavirus infections & Viral disease & $1.74 \mathrm{E}-44$ & 13 & $\begin{array}{l}\text { ACE2, AGT, CCL2, CCL3, CSF3, CXCL10, } \\
\text { IL10, IL2, IL2RA, IL6, IL7, TMPRSS2, TNF }\end{array}$ \\
\hline Nidovirales infections & Viral disease & $1.74 \mathrm{E}-44$ & 13 & $\begin{array}{l}\text { ACE2, AGT, CCL2, CCL3, CSF3, CXCL10, } \\
\text { IL10, IL2, IL2RA, IL6, IL7, TMPRSS2, TNF }\end{array}$ \\
\hline RNA virus infections & Viral disease & 4.92E-27 & 13 & $\begin{array}{l}\text { ACE2, AGT, CCL2, CCL3, CSF3, CXCL10, } \\
\text { IL10, IL2, IL2RA, IL6, IL7, TMPRSS2, TNF }\end{array}$ \\
\hline Virus diseases & Viral disease & $1.73 \mathrm{E}-25$ & 13 & $\begin{array}{l}\text { ACE2, AGT, CCL2, CCL3, CSF3, CXCL10, } \\
\text { IL10, IL2, IL2RA, IL6, IL7, TMPRSS2, TNF }\end{array}$ \\
\hline $\begin{array}{l}\text { Sexually } \\
\text { transmitted } \\
\text { diseases, viral }\end{array}$ & Viral disease & $1.38 \mathrm{E}-12$ & 7 & CCL2, CCL3, IL10, IL2, IL2RA, IL6, TNF \\
\hline HIV infections & Immune system disease, viral disease & $1.56 \mathrm{E}-12$ & 7 & CCL2, CCL3, IL10, IL2, IL2RA, IL6, TNF \\
\hline Lentivirus infections & Viral disease & $1.56 \mathrm{E}-12$ & 7 & CCL2, CCL3, IL10, IL2, IL2RA, IL6, TNF \\
\hline Retroviridae infections & Viral disease & $1.56 \mathrm{E}-12$ & 7 & CCL2, CCL3, IL10, IL2, IL2RA, IL6, TNF \\
\hline $\begin{array}{l}\text { HIV wasting } \\
\text { syndrome }\end{array}$ & $\begin{array}{l}\text { Immune system disease, metabolic } \\
\text { disease, nutrition disorder, viral disease }\end{array}$ & $4.00 \mathrm{E}-04$ & 2 & IL6, TNF \\
\hline $\begin{array}{l}\text { Coxsackievirus } \\
\text { infections }\end{array}$ & Viral disease & 0.001 & 2 & IL6, TNF \\
\hline Enterovirus infections & Viral disease & 0.0044 & 2 & IL6, TNF \\
\hline $\begin{array}{l}\text { Picornaviridae } \\
\text { infections }\end{array}$ & Viral disease & 0.00519 & 2 & IL6, TNF \\
\hline
\end{tabular}

Table 10. Disease network of genes implicated in SARS-COV-2 infection 


\begin{tabular}{|c|c|c|c|c|}
\hline Disease name & P-value & Corrected P-value & Genes & Annotated genes \\
\hline COVID-19 & $1 \mathrm{E}-18$ & $5.44 \mathrm{E}-16$ & 5 & ACE2, AGT, CCL2, TMPRSS2, TNF \\
\hline Pneumonia, viral & $1.56 \mathrm{E}-18$ & 8.46E-16 & 5 & ACE2, AGT, CCL2, TMPRSS2, TNF \\
\hline Coronaviridae infections & $3.4 \mathrm{E}-18$ & $1.85 \mathrm{E}-15$ & 5 & ACE2, AGT, CCL2, TMPRSS2, TNF \\
\hline Coronavirus infections & $3.4 \mathrm{E}-18$ & $1.85 \mathrm{E}-15$ & 5 & ACE2, AGT, CCL2, TMPRSS2, TNF \\
\hline Nidovirales infections & $3.4 \mathrm{E}-18$ & $1.85 \mathrm{E}-15$ & 5 & ACE2, AGT, CCL2, TMPRSS2, TNF \\
\hline Pneumonia & $9.42 \mathrm{E}-15$ & $5.11 \mathrm{E}-12$ & 5 & ACE2, AGT, CCL2, TMPRSS2, TNF \\
\hline Respiratory tract infections & $3.13 \mathrm{E}-13$ & $1.7 \mathrm{E}-10$ & 5 & ACE2, AGT, CCL2, TMPRSS2, TNF \\
\hline RNA virus infections & $2.46 \mathrm{E}-12$ & $1.34 \mathrm{E}-09$ & 5 & ACE2, AGT, CCL2, TMPRSS2, TNF \\
\hline Virus diseases & $9.48 \mathrm{E}-12$ & $5.15 \mathrm{E}-09$ & 5 & ACE2, AGT, CCL2, TMPRSS2, TNF \\
\hline
\end{tabular}

\section{Methods}

All assays were on a fee-for-service contract basis and outsourced to bioanalytical testing companies worldwide. SARS-COV-2 antiviral assays were performed by a bio-safety level 3 (BSL3) facility at the Antiviral research Institute at Utah State University in the USA. The other assays were performed at Southern Research Infectious Disease Research Facility in Frederick, Maryland, USA and IBT Bio services in Rockville, Maryland, USA. ACE2 and TMPRSS2 Assays were carried out by Skanda Life Sciences Pvt Ltd Bangalore, India.

\section{Antiviral assay}

Metadichol was serially diluted using eight half-log dilutions in test medium (MEM supplemented with $2 \%$ FBS and $50 \mu \mathrm{g} / \mathrm{mL}$ gentamicin) so that the starting (high) test concentration was $100 \mu \mathrm{g} / \mathrm{ml}$. Each dilution was added to 5 wells of a $96-$ well plate with $80-100 \%$ confluent Caco- 2 cells.

Three wells of each dilution were inoculated with virus, with two wells uninoculated (as toxicity controls); six wells were inoculated and untreated (as virus controls); and six wells were uninoculated and untreated (as cell controls). SARS-COV-2 was prepared to achieve the lowest possible multiplicity of infection (MOI) that would yield $>80 \%$ cytopathic effect (CPE) within five days. M128533 (protease specific for SARSCOV) was tested in parallel as a positive control. The plates were incubated at $37 \pm 2^{\circ} \mathrm{C}$ and $5 \% \mathrm{CO}_{2}$. On day three post-infection, once untreated virus control wells reached maximum CPE, plates were stained 
with neutral red dye for approximately 2 hours ( \pm 15 minutes). The supernatant dye was removed, and the wells were rinsed with PBS. The incorporated dye was extracted in 50:50 Sorensen citrate buffer/ethanol for $>30$ minutes, and the optical density was read on a spectrophotometer at $540 \mathrm{~nm}$.

Optical densities were converted to percent of that of cell controls, and the concentration of compound that would cause $50 \%$ cell death (CC50) in the absence of virus was calculated by regression analysis. The selective index (SI) is the CC50 divided by the EC90. The results are shown in Table 7.

For a virus yield reduction (VYR) assay, the supernatant fluid from each compound concentration was collected on day three post-infection before neutral red staining ( 3 wells pooled) and tested for virus titre using a standard endpoint dilution CCID50 assay in Vero 76 cells and titre calculations via the ReedMuench (1948) equation. The concentration of compound required to reduce virus yield by one log10 was calculated by regression analysis (EC90).

As shown in Table 2 the virus reduction assay did not follow a typical dose-response relationship, with virus reduction seen at concentrations of $0.3 \mu \mathrm{g} / \mathrm{ml}$ and $3.2 \mu \mathrm{g} / \mathrm{ml}$ but no reduction seen at a concentration of $1 \mu \mathrm{g} / \mathrm{ml}$. It was assumed that breakthrough of the virus at $1 \mu \mathrm{g} / \mathrm{ml}$ was an outlier. The calculated SI was 20 (Table 1), indicating an EC90 of $0.15 \mu \mathrm{g} / \mathrm{ml}$.

The results for other viruses shown in Table 3 and 4 and 5 were carried out in a similar procedure by various labs using Vero cells.

\section{TMPRSS2 inhibition assay}

\section{Procedure}

TMPRSS purified from LNCaP cells (ATCC) was used as an enzyme source. The reaction mixture contained purified TMPRSS2 protease in TBS with or without a range of various concentrations from 1.56 to $100 \mathrm{ng} / \mathrm{ml}$ of test sample or inhibitor. The reaction mixture was incubated for 10 minutes at $37^{\circ} \mathrm{C}$. To the reaction mixture, $1 \mu \mathrm{l}$ of $10 \mathrm{mM}$ the fluorogenic trypsin substrate Cbz-Gly-Gly-Arg-AMC was added, and kinetic fluorescence readings were recorded after 2 minutes of incubation at $37^{\circ} \mathrm{C}$ at Ex383 nm and Em455 nm at 5-10 minutes using a SpectraMax i3X (Molecular Devices). The change in fluorescence (delta RFU) was calculated to determine the inhibitory effects of the test sample. CM (Cayman Chemicals) at a two-fold range of concentrations from 1.56 to $100 \mathrm{nM}$ was used as a positive control for TMPRSS2 protease inhibition.

\section{ACE2 Inhibition assay}


An ACE2 Inhibitor Screening Assay Kit, catalogue no. 79923 (BPS Biosciences, San Diego, USA), was used to measure the exopeptidase activity of ACE2 and inhibition by Metadichol and the control inhibitor DX600. The inhibitory activity was measured based on the fluorescence emitted by the cleavage of a chromogenic substrate.

\section{Procedure}

Enzyme (ACE2) stocks were prepared from the supplied kit. Twenty micro litres of enzyme solution (0.5 $\mathrm{ng} / \mathrm{\mu l}$ ) was added to all the wells designated for the assay. DX600, a potent ACE2 inhibitor, was used as a positive control for ACE2 inhibition at various concentrations ranging from $0.0156 \mu \mathrm{g} / \mathrm{ml}$ to $1 \mu \mathrm{g} / \mathrm{ml}$. The test sample at concentrations ranging from $0.125 \mu \mathrm{g} / \mathrm{ml}$ to $40 \mu \mathrm{g} / \mathrm{ml}$ was used. To each well containing the enzyme solution, $5 \mu$ of inhibitor solution was added to the respective designated wells. The reaction mixture was incubated at room temperature for 5 minutes. After incubation, $25 \mu$ of ACE2 substrate was added to the mixture and incubated for 1 hour at room temperature. The RFU due to cleavage of the substrate were read at Ex555 nm and Em585 nm using a SpectraMax i3x (Molecular Devices). The IC50 values were calculated based on the readings obtained.

\section{Declarations}

\section{Competing interest: Author has no competing interests}

Correspondence and requests for materials should be addressed to raghavan@nanorxinc.com

\section{Glossary Of Gene Descriptions}




\begin{tabular}{|c|c|}
\hline Gene & Description \\
\hline VDR & vitamin $\mathrm{D}$ receptor \\
\hline AHR & aryl hydrocarbon receptor \\
\hline TERT & telomerase reverse transcriptase \\
\hline KL & klotho \\
\hline PAI1 (SERPINE1) & serpin family $\mathrm{E}$ member 1 \\
\hline HIF 1 alpha & hypoxia-inducible factor 1-alpha \\
\hline CCL2 & C-C motif chemokine ligand 2 \\
\hline ICAM1 & intercellular adhesion molecule 1 \\
\hline TNF & tumour necrosis factor \\
\hline ACE & angiotensin I-converting enzyme \\
\hline ACE2 & angiotensin I-converting enzyme 2 \\
\hline AGTR1 (ANG1) & angiotensin II receptor type 1 \\
\hline AGTR2 (ANG2) & angiotensin II receptor type 2 \\
\hline TMPRSS2 & transmembrane serine protease 2 \\
\hline SIRT1 & sirtuin 1 \\
\hline TNF & tumour necrosis factor \\
\hline FURIN & furin, paired basic amino acid cleaving enzyme \\
\hline CD 147 (BSG) & Basigin (BSG), also known as extracellular matrix metalloproteinase inducer \\
\hline IL6 & interleukin 6 \\
\hline IL10 & interleukin 10 \\
\hline CCL3 & C-C motif chemokine ligand 3 \\
\hline IL2 & interleukin 2 \\
\hline IL7 & interleukin 7 \\
\hline CSF3 & Colony-stimulating factor 3 \\
\hline IL2RA & interleukin 2 receptor subunit alpha \\
\hline CXCL8 & C-X-C motif chemokine ligand 8 \\
\hline
\end{tabular}

\section{Figures}


Figure 1

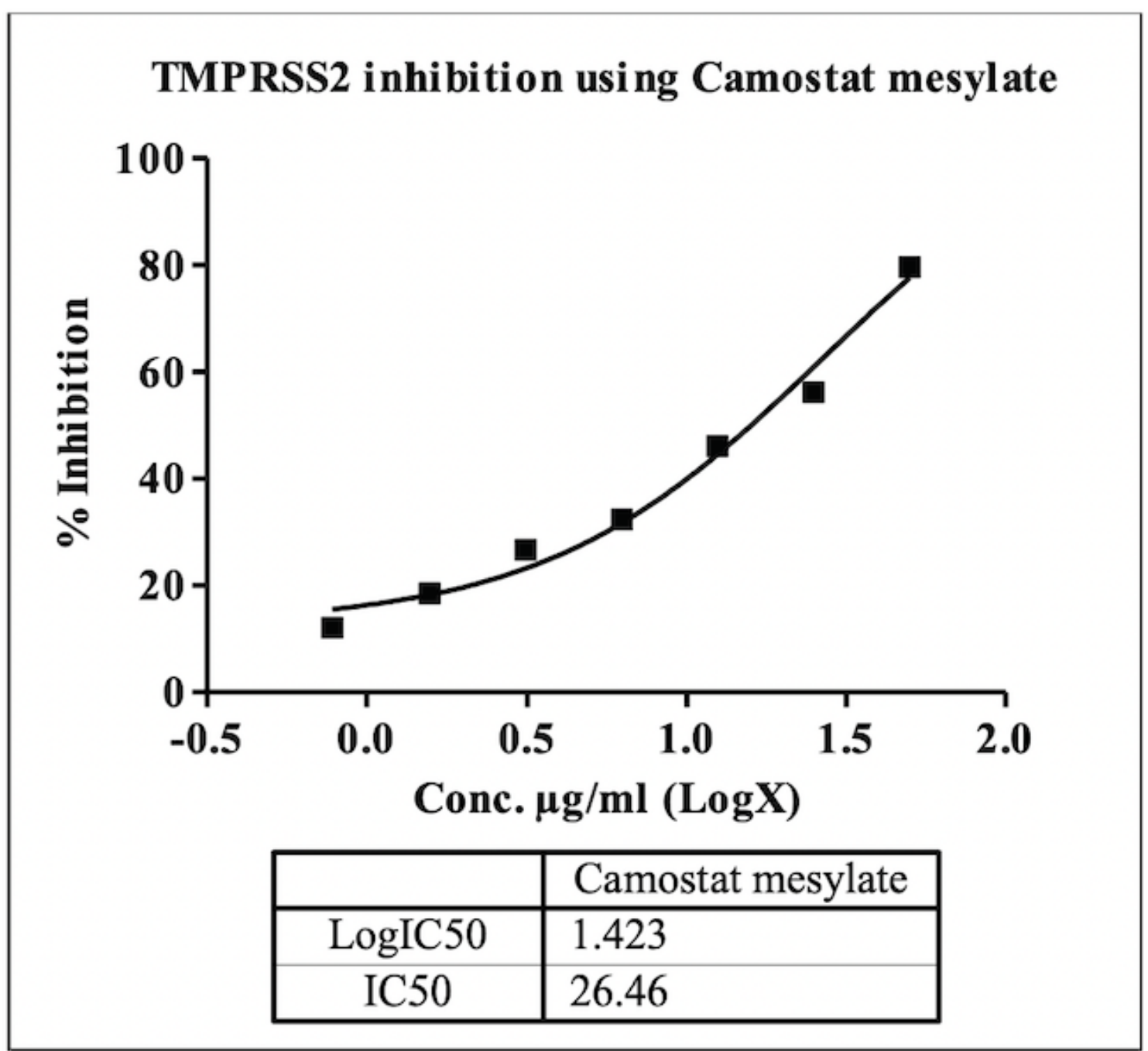

Figure 1

TMPRSS2 inhibition with Camostat mesylate (control) 


\section{Figure 2}

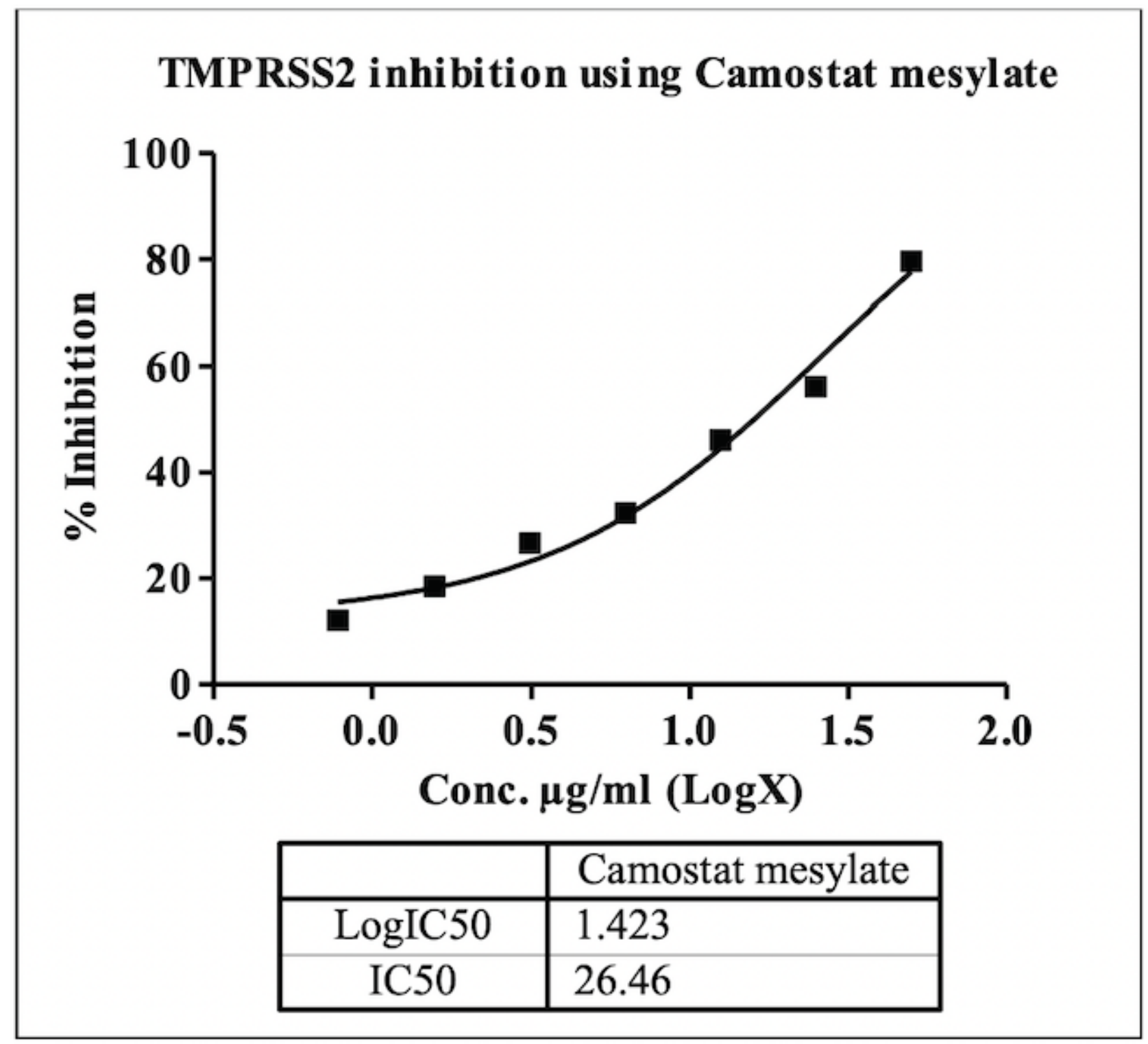

Figure 2

TMPRSS2 inhibition with Metadichol 
Figure 3

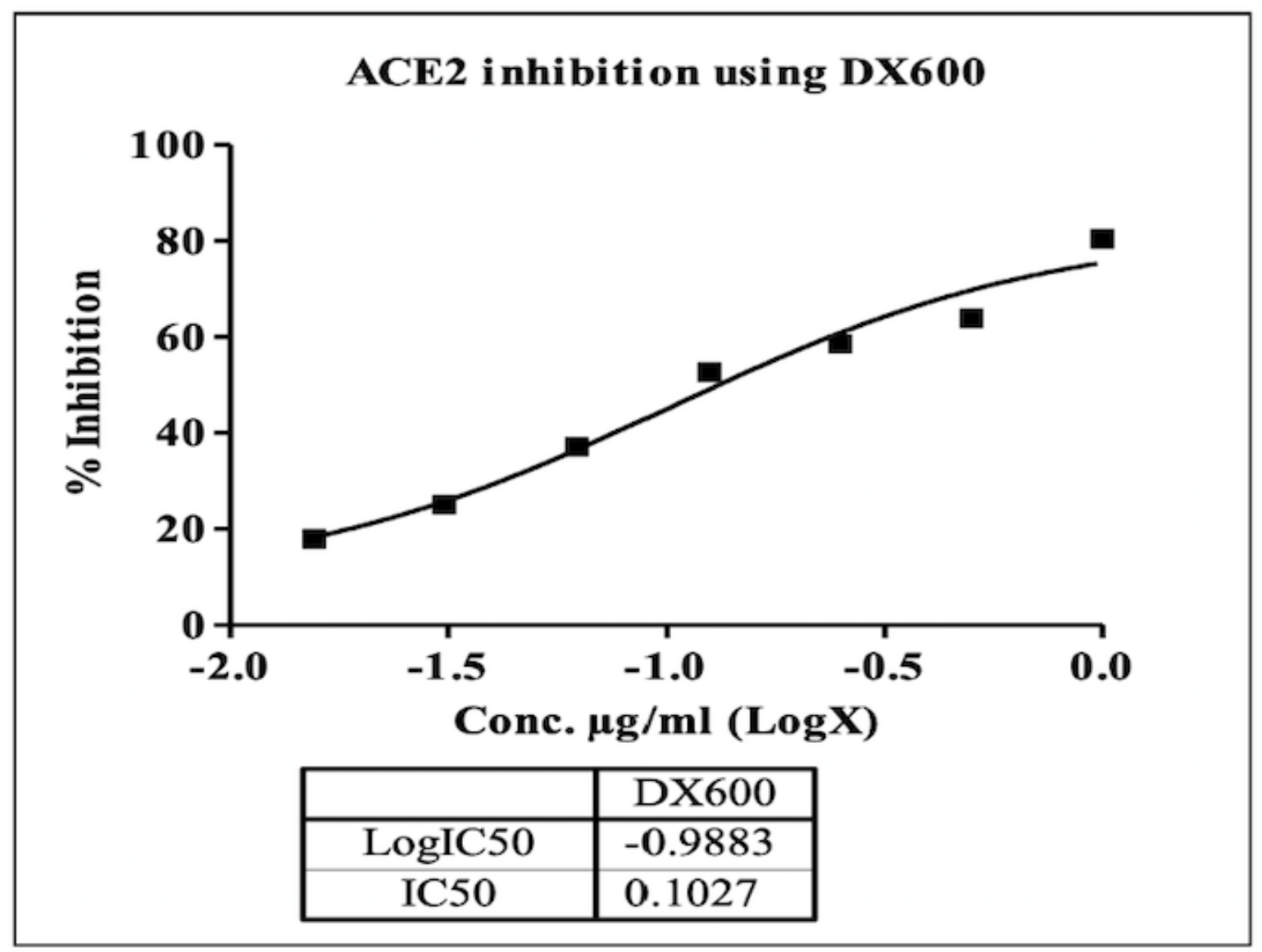

Figure 3

Ace-2 inhibition and DX 600 (control) 
Figure 4

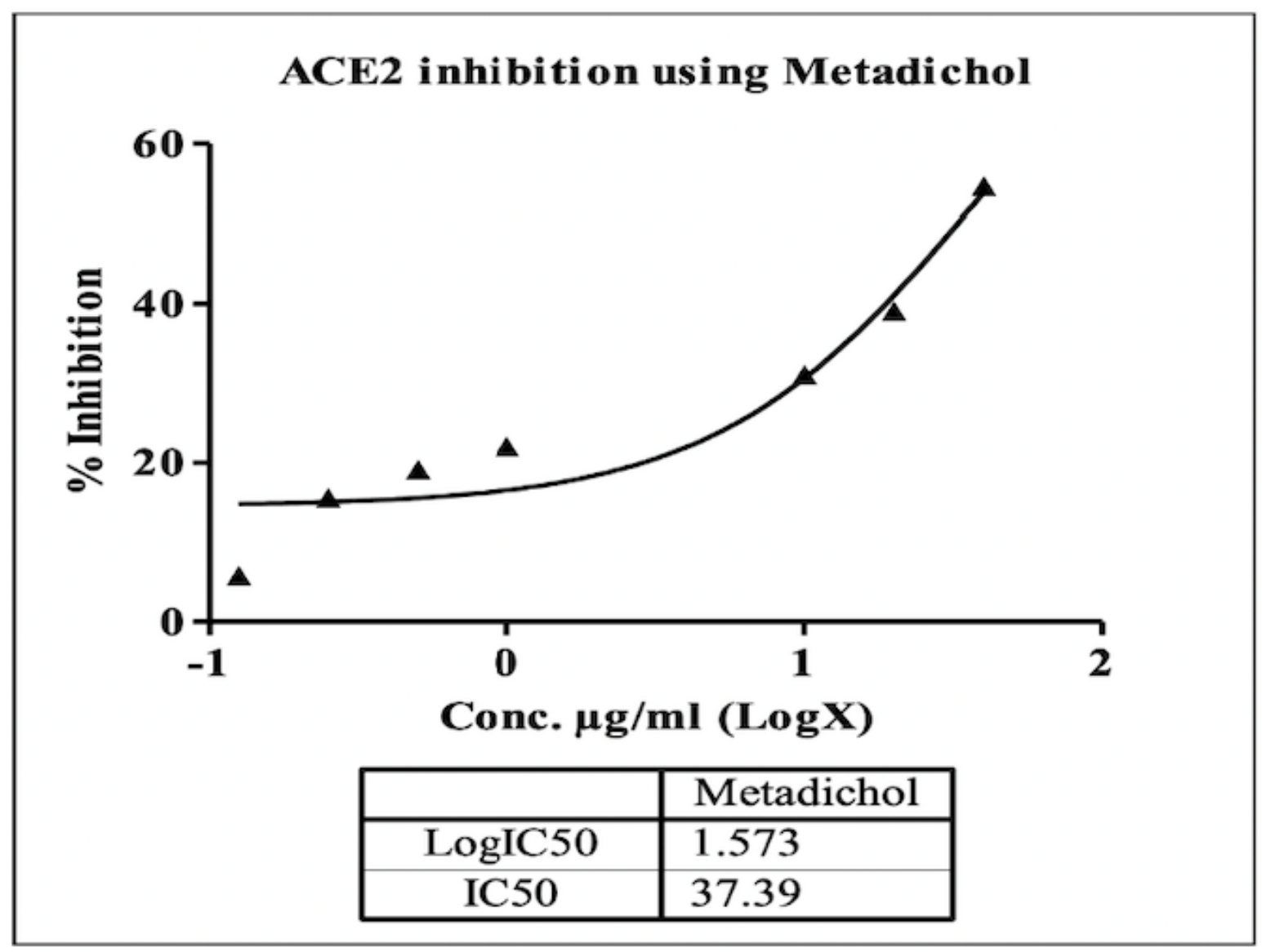

Figure 4

ACE2 inhibition with Metadichol 


\section{Figure 5}

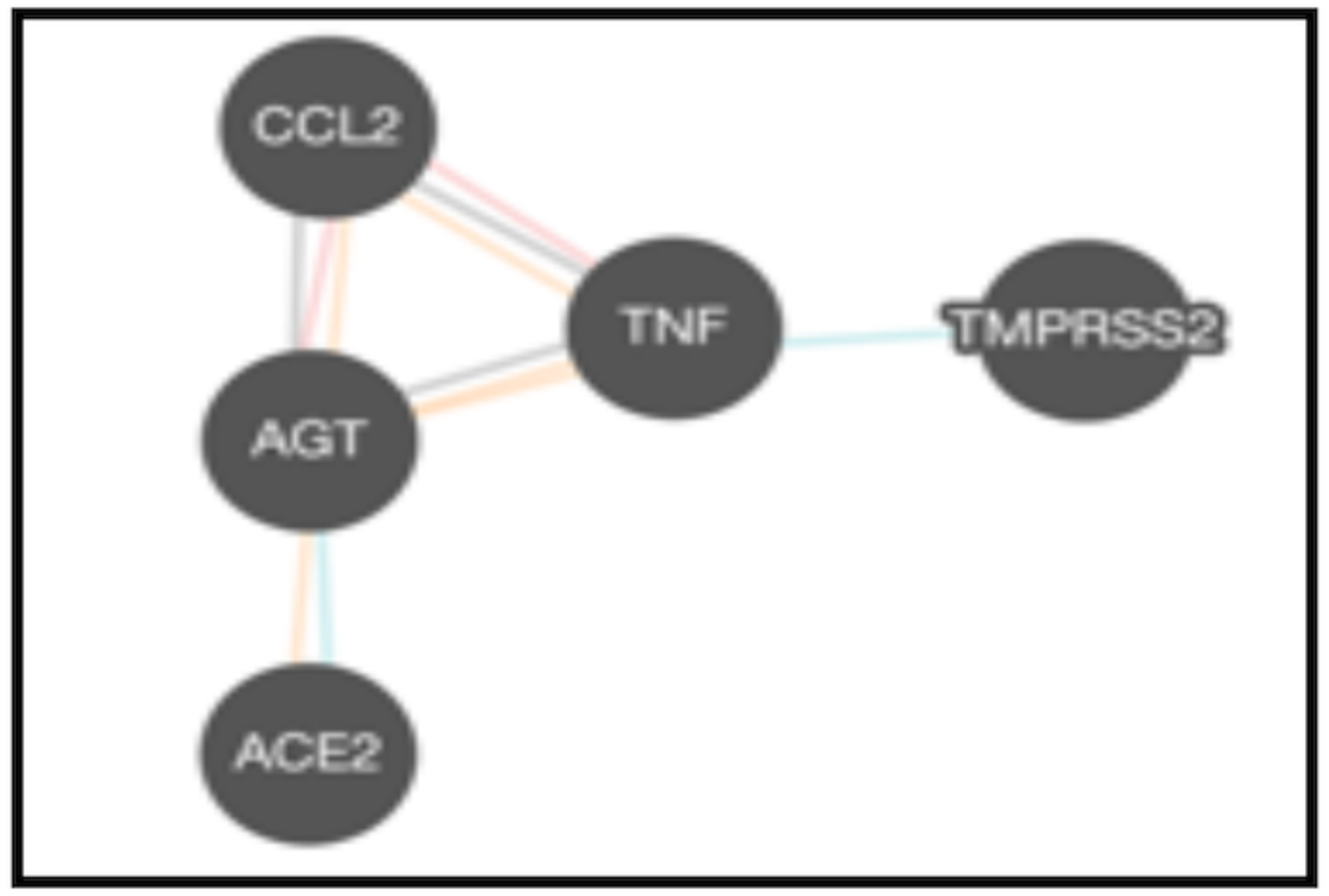

Figure 5

Potential key gene targets in SARS-COV-2 infection 


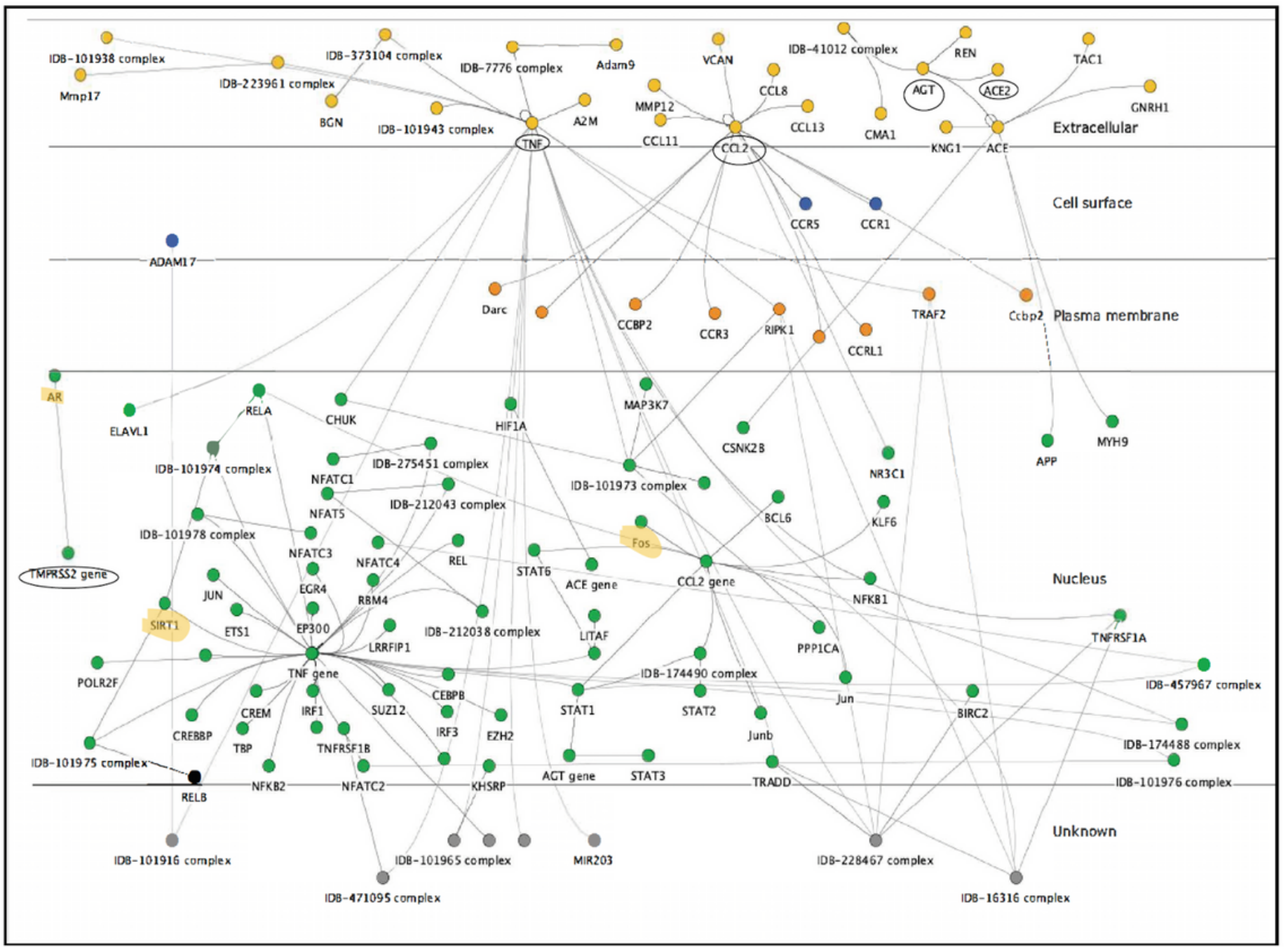

Figure 6

Figure 6

Network analysis of genes involved in SARS-COV-2 infections 


\section{Figure 7}

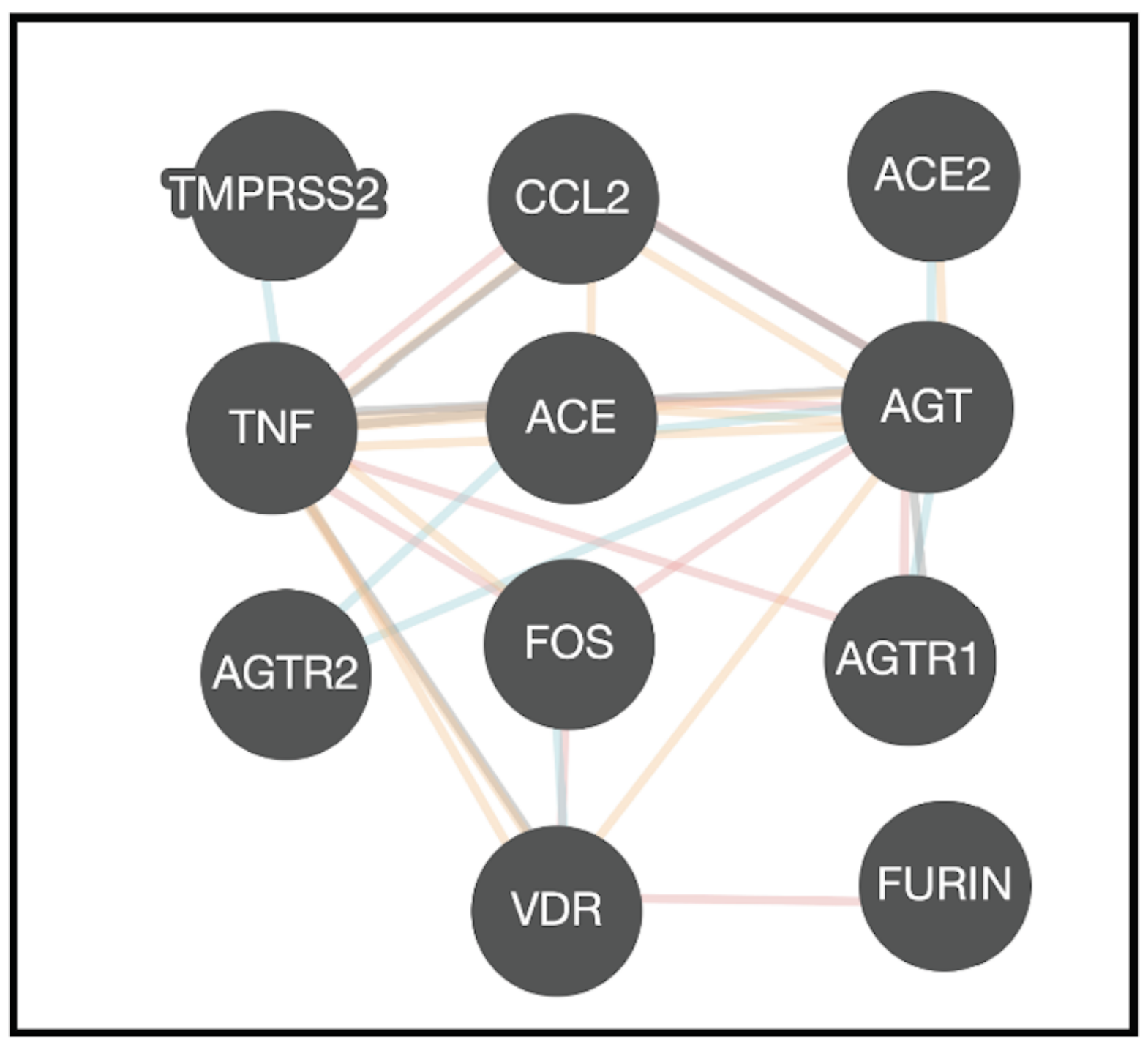

Figure 7

Cytokine relationship and network 
Figure 8

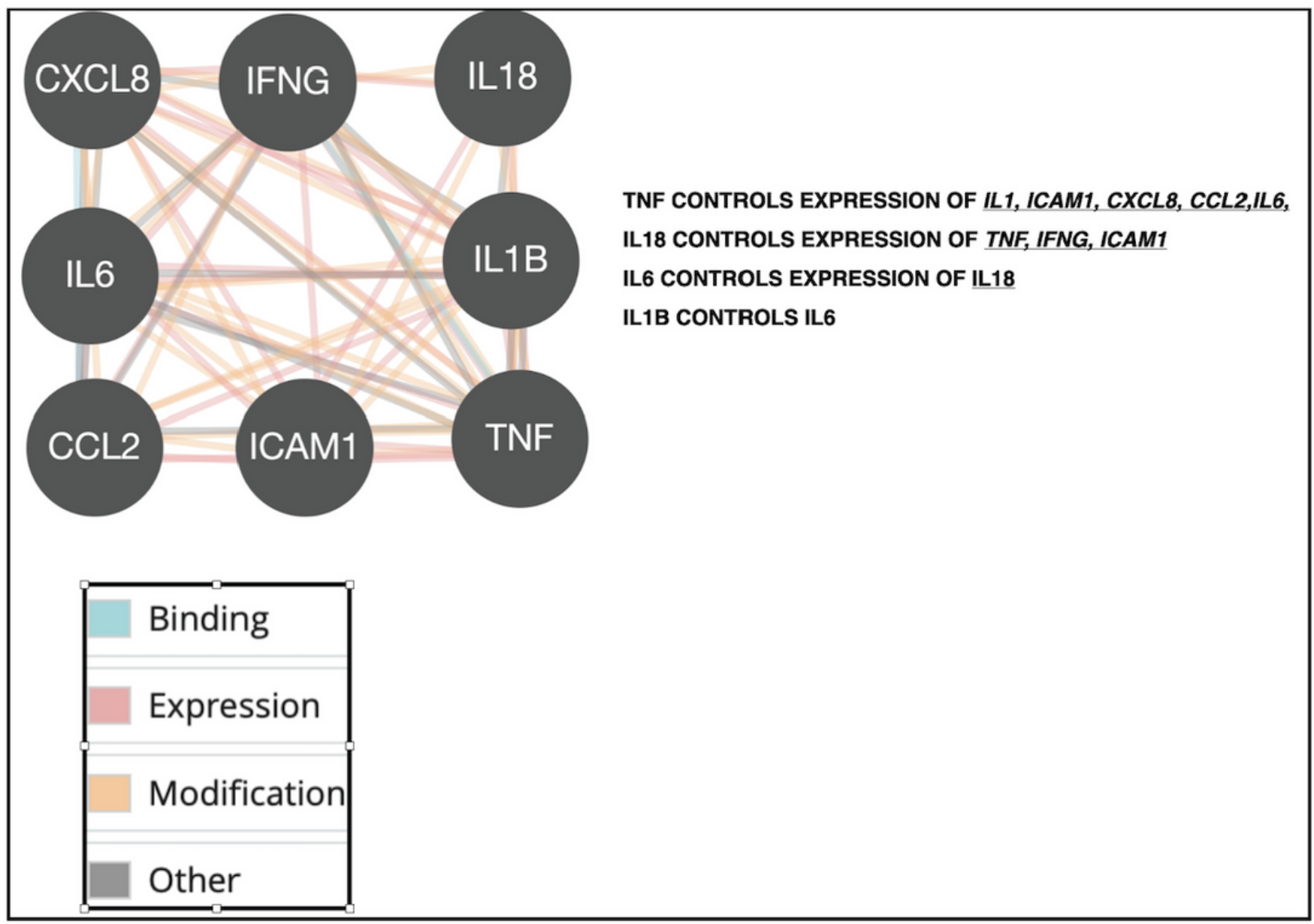

Figure 8

RAS- and VDR-gene relationships 
Figure 9

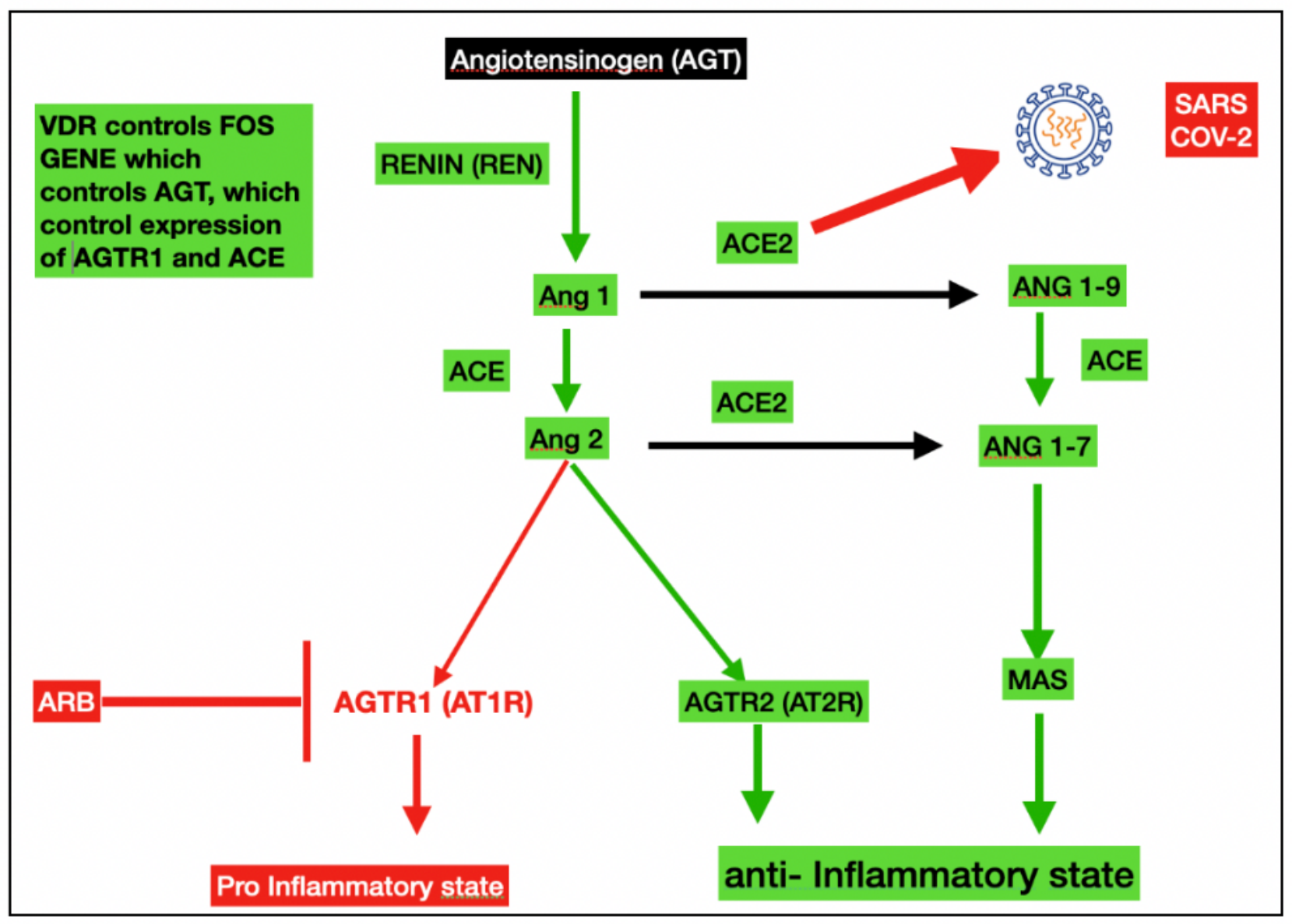

Figure 9

RAS and VDR 